\title{
Synthesis and Antimicrobial Activity of Bis-4,6-sulfonamidated 5,7-Dinitrobenzofuroxans
}

\author{
Irina V. Galkina, ${ }^{1}$ Elena V. Tudriy, ${ }^{1}$ Yuliya V. Bakhtiyarova, ${ }^{1}$ Luiza M. Usupova, ${ }^{2}$ \\ Marina P. Shulaeva, ${ }^{3}$ Oskar K. Pozdeev, ${ }^{3}$ Svetlana N. Egorova, ${ }^{3}$ and Vladimir I. Galkin ${ }^{1}$ \\ ${ }^{1}$ A.M. Butlerov Chemistry Institute, Kazan Federal University, Kazan 420008, Russia \\ ${ }^{2}$ Kazan National Research Technological University, Kazan 420015, Russia \\ ${ }^{3}$ Kazan State Medical University, Kazan 420012, Russia \\ Correspondence should be addressed to Irina V. Galkina; vig54@mail.ru
}

Received 10 March 2014; Revised 22 April 2014; Accepted 23 April 2014; Published 14 May 2014

Academic Editor: Pasupuleti Visweswara Rao

Copyright (C) 2014 Irina V. Galkina et al. This is an open access article distributed under the Creative Commons Attribution License, which permits unrestricted use, distribution, and reproduction in any medium, provided the original work is properly cited.

\begin{abstract}
A new series of bis-4,6-sulfonamidated 5,7-dinitrbenzofuroxans 7-11 had been synthesized and tested for antimicrobial activity. The structures of new sulfanilamide derivatives were characterized by elemental analysis, IR spectroscopy, and mass spectrometry (MALDITOF). The synthesized compounds were tested for their in vitro antimicrobial activity using the disk diffusion method against Gram-positive bacteria Staphylococcus aureus; the Gram-negative bacteria Escherichia coli, Pseudomonas aeruginosa, and Proteus mirabilis; the fungal strain Aspergillus niger; and the yeast-like pathogenic fungus Candida albicans. Our results indicate that the compounds 7-11 exhibit potent antimicrobial activity. The stability of the compounds was evaluated by TG and DSC methods.
\end{abstract}

\section{Introduction}

A need for new antimicrobial agents is justified as more microorganisms develop resistance to the present drugs available in the market. Resistance of pathogenic bacteria to antibiotics is quickly becoming a major problem in the community and hospital-based healthcare settings. The search for novel agents to combat resistant bacteria has become one of the most important areas of antibacterial research today [1]. Some microorganisms are resistant to all approved antibiotics and can only be treated with potentially toxic drugs. Pharmaceutical and organic chemists are trying to synthesize new drugs with better pharmacokinetic and dynamic properties.

Since the discovery of antibacterial properties of the synthetic dye Prontosil over 70 years ago, sulfa drugs have been widely used to treat a broad spectrum of microbial diseases [2-5]. Sulfa drugs kill bacteria and fungi by interfering with cell metabolism. They exert their effect by targeting the synthase dihydropteroate (DHPS) enzyme, which catalyzes folic acid pathway in bacteria and some eukaryotic cells [6] but is not present in human cells [4].
This is the basis for the selective effect of sulfonamides on bacteria and for their broad spectrum of antibacterial activity. A free amino group (only in the para-position) is required for antibacterial activity. The sulfonamide family includes sulfadiazine, sulfamethizole (brand name Thiosulfil Forte), sulfaethylthiadiazole, sulfamethoxazole (Gantanol), sulfathiazole, sulfasalazine (Azulfidine), sulfametopyrazine, sulfisoxazole (Gantrisin), sulfadimethoxine, and various high-strength combinations of three sulfonamides. Before penicillin $G$, these antimicrobials were standard therapies and are still in use today [7].

The benzofuroxans and their chloro-nitro-substituted derivatives have been shown to exhibit a wide spectrum of biological activities [8] and the interest of medicinal chemists in them has grown over the last two decades. Perhaps the most relevant finding reported so far is related to their capability to release nitric oxide; in addition to that, other significant biological activities have been identified, such as antibacterial, antifungal, antiparasitic, cytotoxic, and herbicidal properties [9-12]. Recently, research and development in the medicinal chemistry field have produced hybrid compounds in which benzofuroxanyl moieties are present in 
a single molecule together with classical drug moieties. Consequently, new antiulcer drugs, calcium channel modulators, vasodilator derivatives, antioxidants, and others have been described and are currently under study [13-19]. On the other hand, these kinds of compound have also been reported as components in primary explosives, polymers, and propellants [8, 20-22].

In this paper, we present the synthesis and antimicrobial activity of a series of substituted 5,7-dichloro-4,6-dinitrobenzofuroxan 1 by sulfonamides 2-6, whose chemical structure has been confirmed by IR spectroscopy, mass spectrometry, and elemental analysis.

\section{Experimental}

2.1. Chemistry. All drugs used in this study were purchased from commercial suppliers and satisfy the corresponding pharmacopoeia purity grades. Compound 1 (5,7-dichloro4,6-dinitrobenzofuroxan) was previously synthesized in our laboratory [23]. Compound 2 (sulfanilamide) was purchased from JSC Irbit Pharmaceutical chemistry production plant. Compounds 3-6 (sulfadimethoxine, sulfametopyrazine, sulfathiazole, and sulfaethylthiadiazole) were purchased, respectively, from OJSC “Organica," OJSC "Usolie Siberian Chemical Pharmaceutical Plant," LLC “Asfarma," and OJSC “Centre of the Chemistry for Therapeutic Agents" (all Russia). Penicillin G (sodium salt) and gentamicin (sulfate salt) were purchased from Kurgan JSC "Sintez" (Russia). Rifampicin, chloramphenicol (sodium succinate), nystatin, and ketoconazole were purchased, respectively, from CJSC "Bryntsalov A," OJSC “Organica," OJSC "Biosintez" (all Russia), and Ultratech India Ltd.

The melting points were determined by TG-DSC methods on NETZSCH STA 449 C device and are uncorrected. Elemental microanalyses were performed at Microanalysis Laboratory at Kazan Institute of Organic and Physical Chemistry (Kazan Research Center), Kazan. The IR spectra were recorded on Specord M-80 spectrometer from samples dispersed in mineral oil. To determine molecular masses of compounds obtained, matrix-assisted laser desorption/ionization time of flight mass spectra (MALDI TOF Dynamo Finnigan) was used. The purity of the synthesized compounds was checked using thin layer chromatography (TLC). Evaluation of antimicrobial activities was carried out by the Department of Microbiology, Kazan State Medical Academy, Kazan, Russia.

\subsection{Synthetic Procedure for 4.6-Bis-4,6-sulfonamidated-5.7- dinitrobenzofuroxans (7-11)}

2.2.1. General Procedure. A mixture of equimolar quantities of 5,7-dichloro-4,6-dinitrobenzofuroxan 1 (0.01 mol) and appropriate sulfonamide $(0.04 \mathrm{~mol})$ was refluxed in dry mixture of a ratio of $1: 1$ of EtOH and $\left(\mathrm{C}_{2} \mathrm{H}_{5}\right)_{2} \mathrm{O}(100 \mathrm{~mL})$ for $2 \mathrm{~h}$. Excess of solvent was removed under reduced pressure. The resulting compounds $\mathbf{7 - 1 1}$ were obtained asorange-red crystals and purified by diethyl ether from starting reagents.

7: Yield (74\%), orange crystals, m.p. $199.9^{\circ} \mathrm{C}$. IR (KBr): $3280(\mathrm{~N}-\mathrm{H}), 1616(\mathrm{C}=\mathrm{N}-\mathrm{O}), 1580$ and $1320\left(\mathrm{NO}_{2}\right), 1310$ and $1160\left(\mathrm{SO}_{2}\right) \mathrm{cm}^{-1}$. MS: $m / z 566 \mathrm{M}+\mathrm{H} ; \mathrm{C}_{18} \mathrm{H}_{14} \mathrm{O}_{10} \mathrm{~N}_{8} \mathrm{~S}_{2}$ (566.20): calcd. C 38.16\%, H, 2.47\%, N, 19.79\%; found: C $38.45 \%$, H $2.31 \%$, N $19.99 \%$.

8: Yield (83\%), red crystals, m.p. $190.5^{\circ} \mathrm{C}$. IR (KBr): $3227(\mathrm{~N}-\mathrm{H}), 1630(\mathrm{C}=\mathrm{N}), 1600(\mathrm{C}=\mathrm{N}-\mathrm{O}), 1586$ and 1324 $\left(\mathrm{NO}_{2}\right), 1311$ and $1160\left(\mathrm{SO}_{2}\right) \mathrm{cm}^{-1}$. MS: $\mathrm{m} / z \quad 842 \mathrm{M}+\mathrm{H}$; $\mathrm{C}_{30} \mathrm{H}_{26} \mathrm{O}_{14} \mathrm{~N}_{12} \mathrm{~S}_{2}$ (842.0): calcd. C 42.76\%, H, 3.09\%, N, 19.95\%; found: C 42.88\%, H 3.27\%, N 19.34\%.

9: Yield (67\%), red crystals, m.p. $307.3^{\circ} \mathrm{C}$. IR (KBr): $3260(\mathrm{~N}-\mathrm{H}), 1660(\mathrm{C}=\mathrm{N}), 1616(\mathrm{C}=\mathrm{N}-\mathrm{O}), 1580$ and 1320 $\left(\mathrm{NO}_{2}\right), 1310$ and $1160\left(\mathrm{SO}_{2}\right) \mathrm{cm}^{-1}$. MS: $m / z \quad 782 \mathrm{M}+\mathrm{H}$; $\mathrm{C}_{28} \mathrm{H}_{22} \mathrm{O}_{12} \mathrm{~N}_{12} \mathrm{~S}_{2}$ (782.20): calcd. C 42,97\%, H, 2.81\%, N, 21.48\%; found: C 42.71\%, H 2.77\%, N 21.87\%.

10: Yield (73\%), dark red crystals, m.p. $195.1^{\circ} \mathrm{C} . \mathrm{IR}(\mathrm{KBr})$ : $3280(\mathrm{~N}-\mathrm{H}), 1616(\mathrm{C}=\mathrm{N}-\mathrm{O}), 1580$ and $1320\left(\mathrm{NO}_{2}\right), 1310$ and $1160\left(\mathrm{SO}_{2}\right) \mathrm{cm}^{-1}$. MS: $m / z 732 \mathrm{M}+\mathrm{H} ; \mathrm{C}_{24} \mathrm{H}_{16} \mathrm{O}_{10} \mathrm{~N}_{10} \mathrm{~S}_{4}$ (732.20): calcd. C 39.34\%, H, 2.19\%, N, 19.13\%; found: C $39.17 \%$, H $2.43 \%$, N $19.51 \%$.

11: Yield (84\%), orange crystals, m.p. $197.6^{\circ} \mathrm{C}$. IR (KBr): $3280(\mathrm{~N}-\mathrm{H}), 1665(\mathrm{C}=\mathrm{N}), 1618(\mathrm{C}=\mathrm{N}-\mathrm{O}), 1580$ and 1320 $\left(\mathrm{NO}_{2}\right), 1310$ and $1160\left(\mathrm{SO}_{2}\right) \mathrm{cm}^{-1}$. MS: $\mathrm{m} / z 790 \mathrm{M}+\mathrm{H}$; $\mathrm{C}_{28} \mathrm{H}_{22} \mathrm{O}_{10} \mathrm{~N}_{12} \mathrm{~S}_{4}$ (790.20): calcd. C 39.49\%, H, 2.78\%, N, 21.27\%; found: C 39.07\%, H 2.63\%, N 20.97\%.

2.3. Antimicrobial Screening. Bacterial and fungal strains used in the antimicrobial evaluation were obtained from the Department of Microbiology (Museum of Culture Collections) of Kazan State Medical Academy, Russia, namely, Staphylococcus aureus (ATCC 29213), Escherichia coli (ATCC 25922), Pseudomonas aeruginosa (ATCC 27853), Proteus mirabilis (ATCC 12453), Aspergillus niger (ATCC 16620), and Candida albicans (ATCC 885-653). The antibacterial and antifungal activities were reported utilizing Kirby-Bauer disc diffusion method $[24,25]$. Briefly, agar $(\mathrm{pH}=7.2-$ 7.4; Sabouraud for Candida albicans and Mueller-Hinton for all the others) was placed into Petri dish $(100 \mathrm{~mm}$ size and $4 \mathrm{~mm}$ depth). The agar plates were then inoculated with broth cultures diluted to $0.5 \mathrm{McF}$ arland turbidity ( $1.5 \cdot 10^{8}$ cells $\left.\cdot \mathrm{mL}^{-1}\right)$. Discs containing known amounts of an antimicrobial agent were placed on the surface of an agar plate that has been inoculated with a standardized suspension of microorganisms to be tested. Paper discs with only dimethylsulfoxide (DMSO) or $\mathrm{CH}_{2} \mathrm{Cl}_{2}$ (tests involving Ketoconazole) were used as negative controls. The MZI for rifampicin (antibacterial), nystatin, and ketoconazole (antifungal) was used as reference values (in millimeters). All experiments were conducted in triplicate and repeated if the results differed. All compounds used having MZI larger than or equal to $19 \mathrm{~mm}$ were selected for MIC tests.

For MIC assays $[26,27]$, a stock solution $\left(1 \mathrm{mg} \mathrm{mL}^{-1}\right)$ of each test compound was prepared in DMSO. Further, a serial dilution of test compounds was carried out to achieve concentrations ranging from 50 to $400 \mu \mathrm{g} \cdot \mathrm{mL}^{-1}$. Test compounds at various concentrations were then added to culture medium in a test tube and different strains were inoculated at $10^{8}$ bacteria. $\mathrm{mL}^{-1}$ concentration. Trypticase soy agar and nutrient agar (for antibacterial) and Sabouraud liquid medium (for antifungal) were utilized as culture media. The tubes were incubated at $37^{\circ} \mathrm{C}$ (antibacterial) or $30^{\circ} \mathrm{C}$ 
<smiles></smiles><smiles>NOc1ccc(N)cc1</smiles>

2-6<smiles>[R]NOc1ccc(N)cc1</smiles><smiles></smiles><smiles>[119In]</smiles><smiles>CCc1nnc(Br)s1</smiles>

Scheme 1: Synthetic routes of bis-sulfonamidated 4,6-dinitrobenzofuroxans 7-11; reagents and conditions.

(antifungal) for $24-48 \mathrm{~h}$ and then examined for the growth of the tested organisms or their absence. Chloramphenicol, rifampicin, nystatin, and ketoconazole were used as antibacterial and antifungal substances, respectively. The MIC values were obtained from the lowest concentration of the test compounds where the tubes remained clear, indicating that the bacterial or fungal growth was completely inhibited at this concentration.

\section{Results and Discussions}

3.1. Chemistry. The series of sulfanilamide derivatives 7-11 was synthesized by a substitution reaction between the 5,7-dichloro-4,6-dinitrobenzofuroxan $\mathbf{1}$ and the substituted sulfonamides: 4-aminobenzenesulphonamide 2 (sulfanilamide), 4-(aminobenzenesulphamido)-2,4-dimethoxypyrimidine 3 (sulfadimethoxine), 2-(para-aminobenzenesulphamido)-3methoxypyrazine 4 (sulfametopyrazine), 2-(para-aminobenzenesulphamido)-thiazol 5 (sulfathiazole), and 2-(paraaminobenzenesulfamido)-5-ethyl-1,3,4-thiadiazole 6 (sulfaethylthiadiazole). The synthetic route for the preparation of these molecules is outlined in Scheme 1.

All reactions of 5,7-dichloro-4,6-dinitrobenzofuroxan 1 with sulphonilamides 2-6 were prepared with satisfactory yield and accompanied with intensive change in color of the reaction mixture from orange to red and dark red. On completion of the reactions the precipitated colored crystals were of the synthesized compounds 7-11 purified with ether.

The chemical structures were elucidated on the basis of elemental analysis, IR, and mass spectroscopy. The results of elemental analysis ( $\mathrm{C}, \mathrm{H}$, and $\mathrm{N}$ estimation) were found to be within $\pm 0.4 \%$ of the theoretical values. IR data also confirmed the presence of specific functional groups present in the final synthesized compounds. The mass spectra of new compounds were in conformity with the assigned structure. The melting points and the thermal stability of the compounds were taken from TG and DSC methods.

3.2. Antimicrobial Activity. Compounds $\mathbf{2}-\mathbf{6}$ are historically well-known sulfonamide drugs and have been extensively studied $[5,6,21]$, but microorganisms now often show resistance against them [22]. Compounds 1-2 and all synthesized sulfonamide derivatives 7-11 were tested for antimicrobial activity by the disc diffusion method. In general, these results indicated good antimicrobial activities for all compounds (Table 1). However, some compounds showed significant mean zone inhibition (MZI) for both bacterial and fungal strains: $7(21 \mathrm{~mm}, 20 \mathrm{~mm}$, and $27 \mathrm{~mm}), 8(24 \mathrm{~mm}, 25 \mathrm{~mm}$, and $21 \mathrm{~mm}), \mathbf{9}(18 \mathrm{~mm}, 13 \mathrm{~mm}$, and $20 \mathrm{~mm}), \mathbf{1 0}(25 \mathrm{~mm}$, $21 \mathrm{~mm}$, and $23 \mathrm{~mm})$, and $11(21 \mathrm{~mm}, 21 \mathrm{~mm}$, and $30 \mathrm{~mm})$ against Staphylococcus aureus, Escherichia coli, and Candida albicans, respectively; $8(26 \mathrm{~mm})$ and $\mathbf{1 0}(25 \mathrm{~mm})$ against Pseudomonas aeruginosa; and $\mathbf{1 0}(18 \mathrm{~mm})$ against Aspergillus niger. Among these synthesized compounds, compounds $\mathbf{8}$, 10 , and 11 were found to possess significant antibacterial and antifungal activity when compared to standard antibacterial and antifungal drugs, such as penicillin G, rifampicin, sulfanilamide, ketoconazole, and nystatin. Compounds $\mathbf{7}$ and $\mathbf{9}$ were found to possess antibacterial activity almost equivalent to standard drugs as well as considerable antifungal activity.

To further evaluate antimicrobial potential, we determined the minimum inhibitory concentration (MIC) for the compounds with MZI above or equal to $19 \mathrm{~mm}$. The results (Table 2) show that the tested compounds (especially compounds 8, 10, and 11) possess significant antibacterial and antifungal activities compared to the standard drugs 
TABLE 1: The in vitro antimicrobial activity of the synthesized compounds and the control drugs $(1 \mathrm{mg} / \mathrm{mL})$.

\begin{tabular}{|c|c|c|c|c|c|c|}
\hline \multirow{2}{*}{ Compound number } & \multicolumn{6}{|c|}{ Microorganisms, zone of inhibition (diameter, in $\mathrm{mm}$ ) } \\
\hline & $\begin{array}{c}\text { Staphylococcus } \\
\text { aureus }\end{array}$ & $\begin{array}{c}\text { Escherichia } \\
\text { coli }\end{array}$ & $\begin{array}{c}\text { Pseudomonas } \\
\text { aeruginosa }\end{array}$ & Proteus mirabilis & Aspergillus niger & $\begin{array}{l}\text { Candida } \\
\text { albicans }\end{array}$ \\
\hline 1 & 17 & - & - & - & 10 & 15 \\
\hline Sulfanilamide (2) & 20 & 17 & 15 & 12 & 7 & 9 \\
\hline 7 & 21 & 20 & 7 & 11 & 15 & 27 \\
\hline 8 & 24 & 25 & 26 & 15 & 17 & 21 \\
\hline 9 & 18 & 13 & 18 & 13 & 15 & 20 \\
\hline 10 & 25 & 21 & 25 & 17 & 18 & 23 \\
\hline 11 & 21 & 21 & 10 & 12 & 13 & 30 \\
\hline Penicillin G & 21 & 20 & 8 & 10 & - & - \\
\hline Rifampicin & 25 & 21 & - & - & - & - \\
\hline Ketoconazole & - & - & - & - & 11 & 18 \\
\hline Nystatin & - & - & - & - & 18 & 21 \\
\hline DMSO & - & - & - & - & - & - \\
\hline
\end{tabular}

Shown are mean values of triplicate tests; “-” indicates no significant inhibitory effect $(<6 \mathrm{~mm})$.

TABLE 2: Minimum inhibitory concentration (MIC) of selected compounds.

\begin{tabular}{|c|c|c|c|}
\hline Organism & Compound & $\operatorname{MIC}\left(\mu \mathrm{g} \cdot \mathrm{mL}^{-1}\right)$ & $\operatorname{MIC}(\mu \mathrm{M})$ \\
\hline \multirow{9}{*}{ Staphylococcus aureus } & 1 & 100 & 339 \\
\hline & 7 & 60 & 106 \\
\hline & 8 & 40 & 47 \\
\hline & 9 & 120 & 153 \\
\hline & 10 & 30 & 41 \\
\hline & 11 & 25 & 32 \\
\hline & Chloramphenicol & 45 & 101 \\
\hline & Penicillin G & 70 & 197 \\
\hline & Rifampicin & 50 & 61 \\
\hline \multirow{6}{*}{ Escherichia coli } & 7 & 90 & 159 \\
\hline & 8 & 35 & 42 \\
\hline & 9 & 120 & 153 \\
\hline & 10 & 30 & 41 \\
\hline & 11 & 25 & 32 \\
\hline & Chloramphenicol & 25 & 56 \\
\hline \multirow{3}{*}{ Pseudomonas aeruginosa } & 8 & 30 & 36 \\
\hline & 10 & 30 & 41 \\
\hline & Gentamicin & 55 & 96 \\
\hline \multirow{8}{*}{ Candida albicans } & 1 & 40 & 136 \\
\hline & 7 & 35 & 62 \\
\hline & 8 & 25 & 30 \\
\hline & 9 & 60 & 77 \\
\hline & 10 & 30 & 41 \\
\hline & 11 & 15 & 19 \\
\hline & Ketoconazole & 30 & 56 \\
\hline & Nystatin & 55 & 59 \\
\hline
\end{tabular}

MIC: minimum inhibitory concentration (the lowest concentration that inhibited the bacterial growth). 
(chloramphenicol, rifampicin, penicillin G, and gentamicin for antibacterial activity and ketoconazole and nystatin for antifungal activity).

3.3. Biological Assays. Bacterial and fungal strains used in the antimicrobial evaluation were obtained from the Department of Microbiology (Museum of Culture Collections) of Kazan State Medical Academy, Russia, namely, Staphylococcus aureus (ATCC 29213), Escherichia coli (ATCC 25922), Pseudomonas aeruginosa (ATCC 27853), Proteus mirabilis (ATCC 12453), Aspergillus niger (ATCC 16620), and Candida albicans (ATCC 885-653). The antibacterial and antifungal activities were reported utilizing Kirby-Bauer disc diffusion method [24, 25]. Briefly, agar $(\mathrm{pH}=7.2-7.4$; Sabouraud for Candida albicans and Mueller-Hinton for all the others) was placed into Petri dish (100 $\mathrm{mm}$ size and $4 \mathrm{~mm}$ depth). The agar plates were then inoculated with broth cultures diluted to $0.5 \mathrm{McFarland}$ turbidity $\left(\sim 1.5 \cdot 10^{8}\right.$ cells $\left.\cdot \mathrm{mL}^{-1}\right)$. Discs containing known amounts of an antimicrobial agent were placed on the surface of an agar plate that has been inoculated with a standardized suspension of microorganisms to be tested. Paper discs with only dimethylsulfoxide (DMSO) or $\mathrm{CH}_{2} \mathrm{Cl}_{2}$ (tests involving ketoconazole) were used as negative controls. The MZI for rifampicin (antibacterial) and nystatin and ketoconazole (antifungal) was used as reference values (in millimeters). All experiments were conducted in triplicate and repeated if the results differed. All compounds used having MZI larger than or equal to $19 \mathrm{~mm}$ were selected for MIC tests.

For MIC assays [26, 27], a stock solution $\left(1 \mathrm{mg} \mathrm{mL}^{-1}\right)$ of each test compound was prepared in DMSO. Further, a serial dilution of test compounds was carried out and the concentrations ranged from 50 to $400 \mu \mathrm{g} \cdot \mathrm{mL}^{-1}$. Test compounds at various concentrations were then added to culture medium in a test tube and different strains were inoculated at $10^{8}$ bacteria. $\mathrm{mL}^{-1}$ concentration. Trypticase soy agar and nutrient agar (for antibacterial) and Sabouraud liquid medium (for antifungal) were utilized as culture media. The tubes were incubated at $37^{\circ} \mathrm{C}$ (antibacterial) or $30^{\circ} \mathrm{C}$ (antifungal) for 24-48 $\mathrm{h}$ and then examined for the presence or absence of growth organisms tested. Chloramphenicol, rifampicin, nystatin, and ketoconazole were used as antibacterial and antifungal substances, respectively. The MIC values were obtained from the lowest concentration of the test compounds where the tubes remained clear, indicating that the bacterial or fungal growth was completely inhibited at this concentration.

\section{Conclusions}

A novel series of bis-sulfonamidated 4,6-dinitrbenzofuroxans 7-11, obtained from 5,7-dichloro-4,6-dinitrobenzofuroxan 1 and the substituted sulfonamides $2-6$, were synthesized and characterized based on their physical, analytical, and spectral data. The compounds 7-11 were evaluated in vitro against bacterial and fungal species, showing significant antimicrobial activities. These new data of the molecules $\mathbf{8}$ and $\mathbf{1 0}$ might be helpful in the future development of sulfanilamide analogues as novel antimicrobial agents.

\section{Conflict of Interests}

The authors declare that there is no conflict of interests regarding the publication of this paper.

\section{Acknowledgment}

The authors thank the Academy of Sciences of Tatarstan Republic, Russia, for financial support of this research work.

\section{References}

[1] G. Aysel, I. Taylan, T. Nalan, and O. Gulten, "Synthesis and antimicrobial evaluation of some novel imidazolylmercaptoacetylthio semicarbazide and 4-thiazolidinone analogs," Turkish Journal of Pharmaceutical Sciences, vol. 2, no. 1, pp. 134136, 2005.

[2] B. L. Wilkinson, L. F. Bornaghi, A. D. Wright, T. A. Houston, and S. A. Poulsen, "Anti-mycobacterial activity of a bissulfonamide," Bioorganic and Medicinal Chemistry Letters, vol. 17, no. 5, pp. 1355-1357, 2007.

[3] A. Scozzafava, T. Owa, A. Mastrolorenzo, and C. T. Supuran, "Anticancer and antiviral sulfonamides," Current Medicinal Chemistry, vol. 10, no. 11, pp. 925-953, 2003.

[4] S. Joshi and N. Khosla, "QSAR study on antibacterial activity of sulphonamides and derived Mannich bases," Bioorganic and Medicinal Chemistry Letters, vol. 13, no. 21, pp. 3747-3751, 2003.

[5] A. Alsughayer, A. Elassar, S. Mustafa, and F. Sagheer, "Synthesis, structure analysis and antibacterial activity of new potent sulfonamide derivatives," Journal of Biomaterials and Nanobiotechnology, vol. 2, no. 2, pp. 144-149, 2011.

[6] B. G. Katzung, Basic and Clinical Pharmacology, University of California, San Francisco, Calif, USA, 1995.

[7] Y. Genc, R. Ozkanca, and Y. Bekdemir, "An overview on some benzimidazole and sulfonamide derivatives with anti-microbial activity," Annals of Clinical Microbiology and Antimicrobials, vol. 7, no. 17, pp. 17-25, 2008.

[8] H. Cerecetto and M. Gonzales, "Benzofuroxan and furoxan. Chemistry and biology," Topics in Heterocyclic Chemistry, vol. 10, pp. 265-308, 2007.

[9] H. Bohn, J. Brendel, P. A. Martorana, and K. Schonafinger, "Cardiovascular actions of the furoxan CAS 1609, a novel nitric oxide donor," British Journal of Pharmacology, vol. 114, no. 8, pp. 1605-1612, 1995.

[10] C. Medana, G. Ermondi, R. Fruttero, A. Di Stilo, C. Ferretti, and A. Gasco, "Furoxans as nitric oxide donors. 4-Phenyl3-furoxancarbonitrile: thiol-mediated nitric oxide release and biological evaluation," Journal of Medicinal Chemistry, vol. 37, no. 25, pp. 4412-4416, 1994.

[11] L. Mu, S. S. Feng, and M. L. Go, "Study of synthesis and cardiovascular activity of some furoxan derivatives as potential NO-donors," Chemical and Pharmaceutical Bulletin, vol. 48, no. 6, pp. 808-816, 2000.

[12] M. Feelisch, K. Schonafinger, and E. Noack, “Thiol-mediated generation of nitric oxide accounts for the vasodilator action of furoxans," Biochemical Pharmacology, vol. 44, no. 6, pp. 11491157, 1992.

[13] H. Cerecetto and W. Porcal, "Pharmacological properties of furoxans and benzofuroxans: recent developments," MiniReviews in Medicinal Chemistry, vol. 5, no. 1, pp. 57-71, 2005. 
[14] K. J. Hwang, S. M. Park, H. S. Kim, and S. H. Lee, "Pharmacological properties of furoxans and benzofuroxans," Bioscience Biotechnology and Biochemistry, vol. 62, pp. 1693-1699, 1998.

[15] C. Olea-Azar, C. Rigol, F. Mendizábal et al., "Novel benzo[1,2c]1,2,5-oxadiazole $\mathrm{N}$-oxide derivatives as antichagasic agents: chemical and biological studies," Letters in Drug Design and Discovery, vol. 2, no. 4, pp. 294-301, 2005.

[16] W. Porcal, P. Hernández, G. Aguirre et al., "Second generation of 5-ethenylbenzofuroxan derivatives as inhibitors of Trypanosoma cruzi growth: synthesis, biological evaluation, and structure-activity relationships," Bioorganic and Medicinal Chemistry, vol. 15, no. 7, pp. 2768-2781, 2007.

[17] I. V. Galkina, S. N. Egorova, L. M. Usupova et al., "Anthelminthic composition of quaternary phosphonium salt and substituted dinitrobenzofuroxane," RU Patent 2413513, 2011.

[18] I. V. Galkina, G. L. Tahautdinova, E. V. Tydriy et al., "Meisenheimer complexes with bactericide and fungicide activity," RU Patent 2452730, 2012.

[19] I. V. Galkina, G. L. Tahautdinova, E. V. Tydriy et al., "Synthesis and structure of Meisenheimer adducts in nucleophilic aromatic amination of 4,6-dinitrobenzofuroxan," Russian Journal of Organic Chemistry, vol. 49, pp. 598-602, 2013.

[20] T. J. Janssen, Ed., Explosive Materials: Classification, Composition and Properties, Materials Science and Technologies: Chemical Engineering Methods and Technology, Nova Science Publishers, New York, NY, USA, 2011.

[21] D. S. Reeves, "Laboratory and clinical studies with sulfametopyrazine as a treatment for bacteriuria in pregnancy," Journal of Antimicrobial Chemotherapy, vol. 1, no. 2, pp. 171-186, 1975.

[22] K. J. Cummings, G. A. Perkins, S. M. Khatibzadeh, L. D. Warnick, and C. Altier, "Antimicrobial resistance trends among Salmonella isolates obtained from dairy cattle in the northeastern United States, 2004-2011," Foodborne Pathogenes Disease, vol. 10, no. 4, pp. 353-361, 2013.

[23] E. E. Kanchurina, Synthetic procedure of nitrobenzofuroxane derivatives as potential flame retardants [Ph.D. thesis], Kazan State University, Kazan, Russia, 2007.

[24] J. H. Jorgensen, J. D. Turnidge, and J. A. Washington, "Antibacterial susceptibility tests: dilution and disk diffusion methods," in Mannual of Clinical Microbiology, P. R. Murray, M. A. Pfaller, F. C. Tenover, E. J. Baron, and R. H. Yolker, Eds., pp. 1526-1543, ASM Press, Washington, DC, USA, 7th edition, 1999.

[25] National Committee for Clinical Laboratory Standards (NCCLS), Performance Standards for Antimicrobial Disk Susceptibility Tests, Approved standard publication M2-A5, NCCLS, Villanova, Pa, USA, 5th edition, 1993.

[26] National Committee for Clinical Laboratory Standards (NCCLS), Methods for Dilution Antimicrobial Susceptibility Tests for Bacteria That Grow Aerobically, Approved standard NCCLS publication M7-A3, NCCLS, Villanova, Pa, USA, 3rd edition, 1993.

[27] National Committee for Clinical Laboratory Standards (NCCLS), Reference Method for Broth Dilution Antifungal Susceptibility Testing of Yeasts, Proposed standard NCCLS Document M27-p, NCCLS, Villanova, Pa, USA, 1992. 

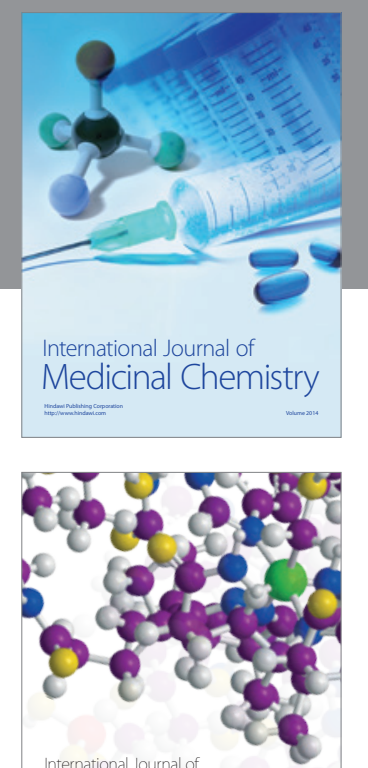

\section{Carbohydrate} Chemistry

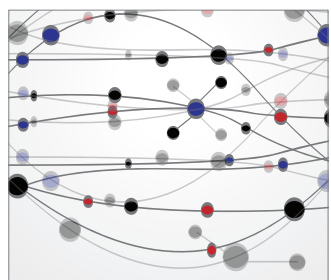

The Scientific World Journal
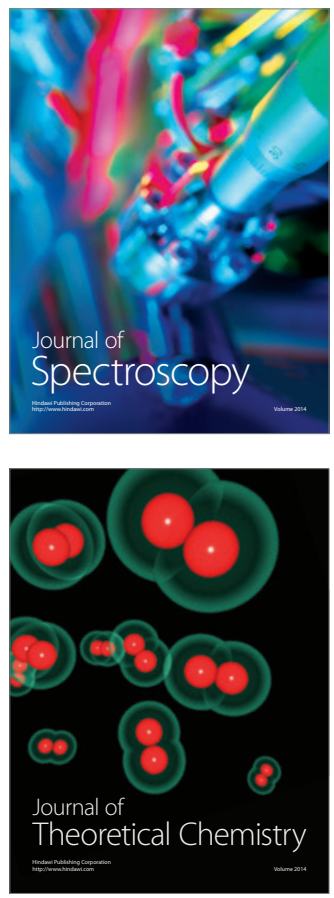
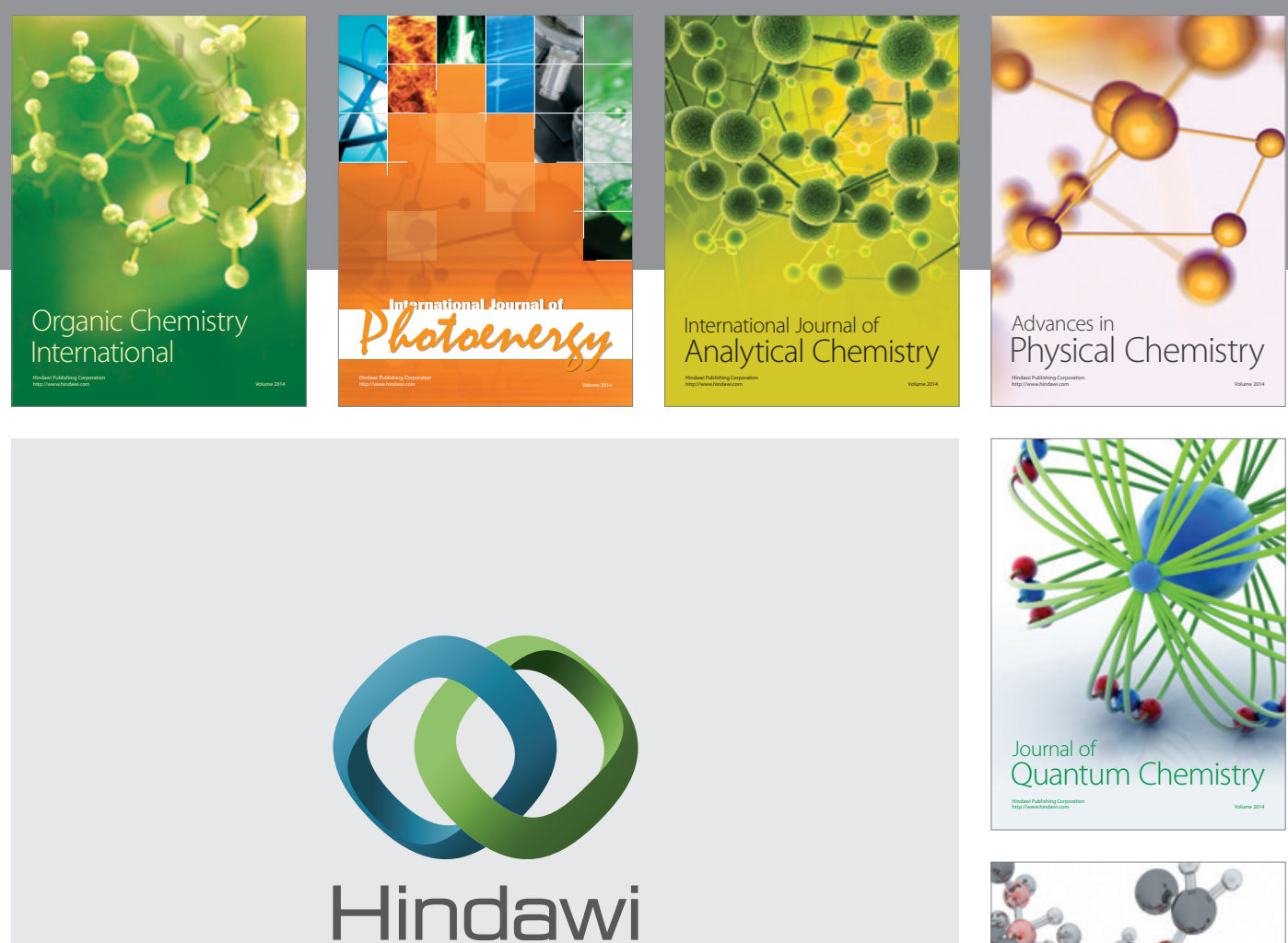

Submit your manuscripts at

http://www.hindawi.com

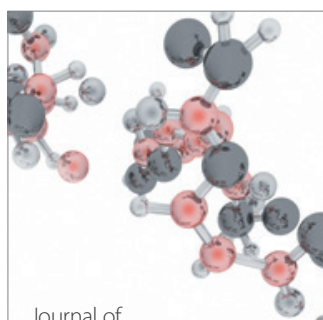

Analytical Methods

in Chemistry

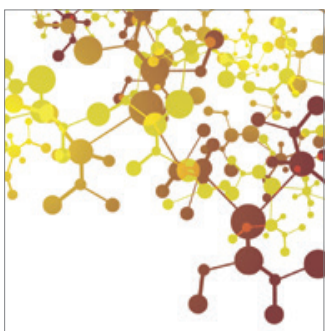

Journal of

Applied Chemistry

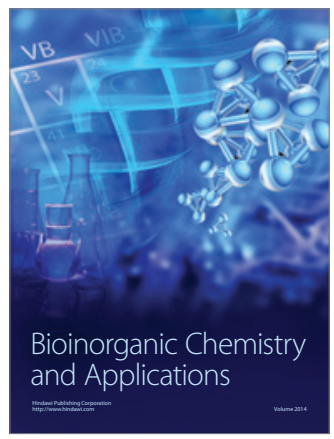

Inorganic Chemistry
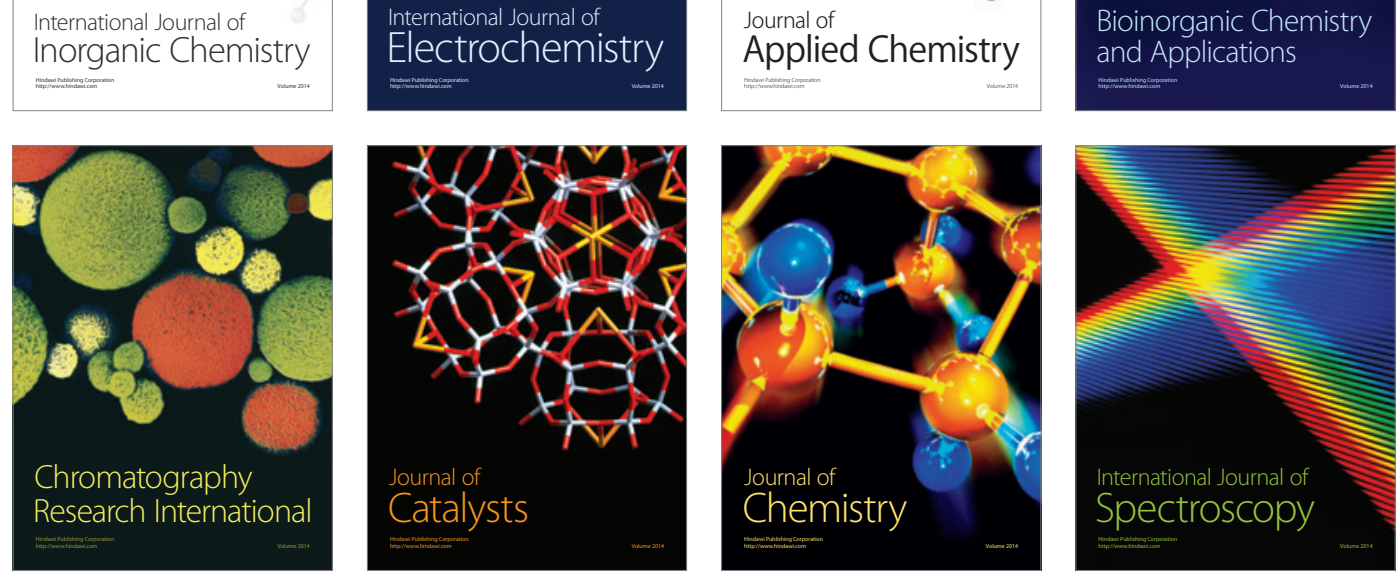